\author{
Wladyslaw Koc \\ Prof. dr hab. inż. \\ Politechnika Gdańska, Wydział Inżynierii Lądowej i Środowiska \\ kocwl@pg.gda.pl
}

DOI: 10.35117/A_ENG_16_04_01

\title{
Extending transition curve in analytical design method
}

\begin{abstract}
The paper presents the problem of extending the transitional curves, using for this purpose an analytical design method. The basis for the analysis of numerical calculations were carried out for a wide set of parameters characterizing the standard geometric system. We considered an importance of the size of radius of the circular arc and return angle of route on the obtained results after the formulation of appropriate theoretical dependence. It was found that the extension of the transition curve does not need cause large lateral displacements of the existing track at considerable length. It is only necessary to reduce the radius of the circular arc in a suitable way.
\end{abstract}

Keywords: Railway track; geometric system; transition curves; analysis of horizontal ordinates

\section{Introduction}

The necessity of extending the transition curves is a common problem occurring in the modernization of the railway line. Radii of circular arcs on lines built in the past allow very often raising train speed by increasing lean, but the leant ramp can turn out then too short. The need to extend the leant ramp means at the same time the extending the transition curve, leading to a horizontal shift of the position the circular arc. These shifts may consequently mean the need for the reconstruction of substructure. Therefore, efforts should be made to maintain the necessary lateral displacements of the track in the specified limits.

In his fundamental work [1], H. Bałuch devoted a separate chapter on the optimization of the extension of transitional curves. He described in detail two ways of extending these curves. One relies on the deviation of the tangent to the arc and the second by reducing the basic radius of the arc. While the first method may raise some doubts [4], the second has certainly its justification. These methods were used in the pre-modernization diagnostics of system DIMO [2,3].

The solutions presented in [1] were obtained in a conventional manner in a coordinate system of a single transition curve, wherein the abscissa axis is defined by the attached straight sections of the route. Then there are in them some simplifying assumptions [8] and the angle of return route is not included.

Analytical design method opens up new possibilities in determining the effectiveness of the process of extending the transitional curves $[5,6,7]$. In this study, it will be presented results of numerical calculations carried out using algorithms of the mentioned method for a wide set of parameters characterizing the standard geometric system.

\section{General assumptions}

We assume the standard case, comprising a geometric system consisting of a circular arc and two transition curves of the same type and with the same length. Due to the symmetry, it is enough to consider only one half of the system.

Design data are as follows: 
$\alpha-$ angle of direction return of the main route,

$R$ - radius of the circular arc in the original geometrical system,

$l_{k}$ - the length of transition curves (of a specific type) in the original geometric system,

$l_{w}$ - the length of the elongated transitional curves (of a specific type),

$R_{w}$ - radius of the circular arc in the geometrical system of elongated transition curves.

The length $l_{R}$ of the circular arc is the result value, closing the designed geometrical system.

Elongation process of the transition curve is illustrated by the diagram in Figure 1. The existing transition curve, extending from point $O$ to point $K$, is located in the coordinate system $x, y$. To extend it, we should move its starting point to the left, along the direction of the main route. The beginning of an extended transition curve $\bar{O}$ determines the position of its coordinate system $\bar{x}, \bar{y}$.

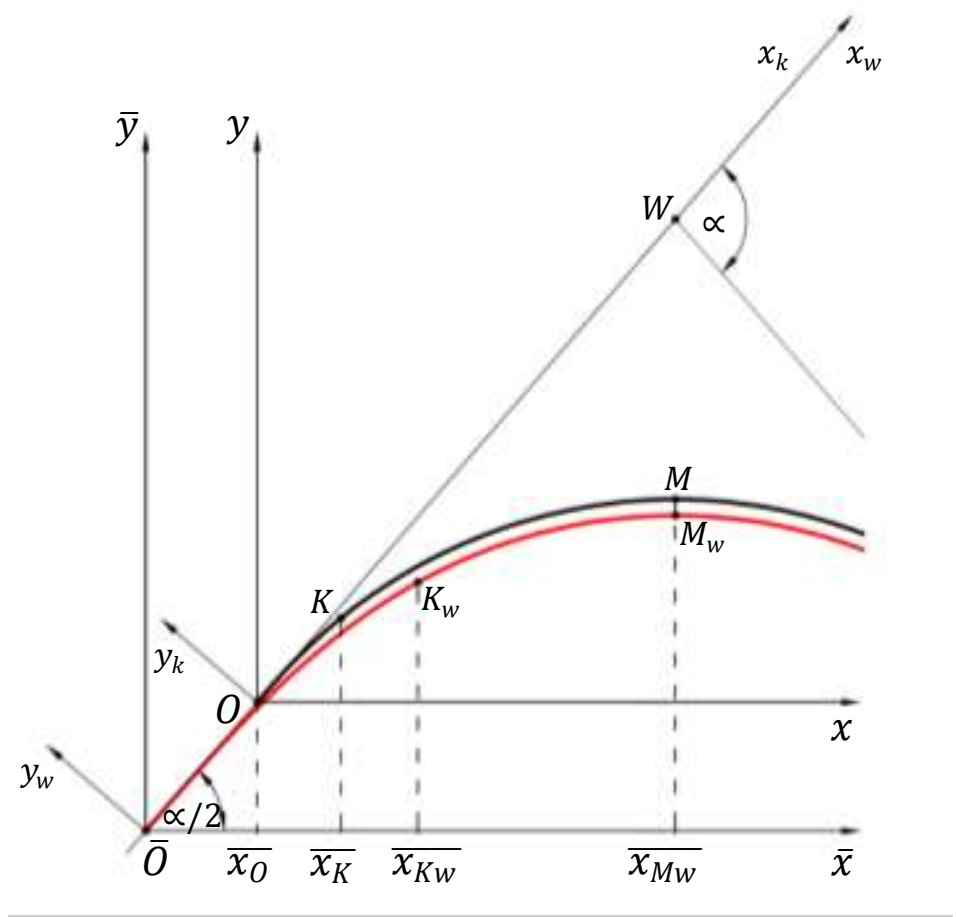

1. Diagram illustrating the process of extending the transition curve

The existing transition curve combines with the circular arc at the point $K$, maintaining the tangency condition. The extended transition curve joins tangently with the circular arc at the point $K_{w}$. Between the two curves there is a difference of horizontal ordinate. The value of this difference in the end region, i.e. between points $M$ and $M_{w}$, can be reduced by changing the radius of the circular arc (along with any change in the type of transition curve).

\section{Analytical description of geometrical system}

Analysis of the problem of extending the transitional curves will be carried out using an analytical design method. Suitable theoretical dependencies of this case are presented in [51].

Original geometric system in the coordinate system $x, y$

Existing transition curve in a coordinate system $x, y$ is described by the following parametric equations:

$$
x_{1}(l)=x_{k}(l) \cos \frac{\alpha}{2}-y_{k}(l) \sin \frac{\alpha}{2}
$$




$$
y_{1}(l)=x_{k}(l) \sin \frac{\alpha}{2}+y_{k}(l) \cos \frac{\alpha}{2}
$$

where a parameter $l \in\left\langle 0, l_{k}\right\rangle$, and $x_{k}(l), y_{k}(l)$ are equation of the curve in the auxiliary coordinate system $x_{k}, y_{k}$ (Fig. 1). In the case of the transitional curve in the form of clothoid is described by:

$$
\begin{aligned}
& x_{k}(l)=l-\frac{l^{5}}{40 R^{2} l_{k}^{2}}+\frac{l^{9}}{3456 R^{4} l_{k}^{4}} \ldots \\
& y_{k}(l)=-\frac{l^{3}}{6 R l_{k}}+\frac{l^{7}}{336 R^{3} l_{k}^{3}}-\frac{l^{11}}{42240 R^{5} l_{k}^{5}}-\ldots
\end{aligned}
$$

The slope of the tangent at the end of the initial transient curve, i.e. at the point $K\left(x_{K}, y_{K}\right)$, is:

$$
S_{K}=\tan \left(-\frac{l_{k}}{2 R}+\frac{\alpha}{2}\right)
$$

whereas the coordinates of this point are determined from the equation (1), (2) for $l=l_{k}$.

Due to the geometric symmetry of the system, in the half of the original circular arc, i.e. at the point $M$, the slope of the tangent $s_{M}=0$, and the coordinates of this point are as follows:

$$
\begin{gathered}
x_{M}=x_{K}+\frac{s_{K}}{\left(1+s_{K}^{2}\right)^{\frac{1}{2}}} R \\
y_{M}=y_{K}+\left[1-\frac{1}{\left(1+s_{K}^{2}\right)^{\frac{1}{2}}}\right] R
\end{gathered}
$$

Geometric system of the elongated transition curves in the coordinate system $\bar{x}, \bar{y}$

The elongated transition curve is described in the coordinate system $\bar{x}, \bar{y}$ by parametric equations:

$$
\begin{aligned}
& \overline{x_{2}}(l)=x_{w}(l) \cos \frac{\alpha}{2}-y_{w}(l) \sin \frac{\alpha}{2} \\
& \overline{y_{2}}(l)=x_{w}(l) \sin \frac{\alpha}{2}+y_{w}(l) \cos \frac{\alpha}{2}
\end{aligned}
$$

where parameter $l \in\left\langle 0, l_{w}\right\rangle, x_{w}(l), y_{w}(l)$ are equations of the curve in the auxiliary coordinate system $x_{w}, y_{w}$ (Fig. 1). The slope of the tangent at the end of the elongated transition curve, i.e. at the point $K_{w}\left(\overline{x_{K w}}, \overline{y_{K w}}\right)$ is

$$
\overline{S_{K w}}=\tan \left(-\frac{l_{w}}{2 R}+\frac{\alpha}{2}\right)
$$

whereas the coordinates of this point are determined from the equation (6), (7) for $l=l_{w}$. 
As in the case of point $M$, in the half of the circular arc of the elongated transition curves, i.e. at the point $M_{w}$, the slope of the tangent $\overline{S_{M w}}=0$ the coordinates of this point are as follows:

$$
\begin{gathered}
\overline{x_{M w}}=\overline{x_{K w}}+\frac{\overline{s_{K w}}}{\left(1+{\overline{S_{K w}}}^{2}\right)^{\frac{1}{2}}} R \\
\overline{y_{M w}}=\overline{y_{K w}}+\left[1-\frac{1}{\left(1+\overline{S_{K w}}\right)^{\frac{1}{2}}}\right] R
\end{gathered}
$$

\section{Determination of the difference in horizontal ordinates}

The analysis of the process of extending the transition curves will be based on the assessment of differences in horizontal ordinates in the existing geometric and modified systems. Since the whole procedure will take place in the coordinate system $\bar{x}, \bar{y}$, it should be specified the location of the existing transition curve in the same system.

The begging of the existing transition curve has in the coordinate system $\bar{x}, \bar{y}$ the following coordinates:

$$
\begin{gathered}
\overline{x_{0}}=\overline{x_{M w}}-x_{M} \\
\overline{y_{0}}=\left(\overline{x_{M w}}-x_{M}\right) \tan \frac{\alpha}{2}
\end{gathered}
$$

Coordinates of the existing circular arc are as follows:

$$
\begin{gathered}
\overline{x_{M}}=\overline{x_{M w}} \\
\overline{y_{M}}=y_{M}+\left(\overline{x_{M w}}-x_{M}\right) \tan \frac{\alpha}{2}
\end{gathered}
$$

The difference in horizontal ordinates of the center of circular arc between the existing system and the system of transitional elongated curves is

$$
\Delta y_{M}=\overline{y_{M}}-\overline{y_{M w}}
$$

The value $\Delta y_{M}$ is an approximate indicator of crosswise displacements of the existing geometrical system. However, to get a full picture of the situation, differences in ordinates along the entire length of the system should be determined, i.e. for $\bar{x} \in\left\langle 0, \overline{x_{M w}}\right\rangle$. In the coordinate system $\bar{x}, \bar{y}$ parametric equations of the original transition curve are denoted by $\overline{x_{1}}(l)$ and $\overline{y_{1}}(l)$. They are as follows:

$$
\overline{x_{1}}(l)=\overline{x_{0}}+x_{1}(l), \overline{y_{1}}(l)=\overline{y_{0}}+y_{1}(l), l \in\left\langle 0, l_{k}\right\rangle
$$

The procedure is different for four intervals of abscissa $\bar{x}: \bar{x} \in\left\langle 0, \overline{x_{O}}\right\rangle, \bar{x} \in\left\langle\overline{x_{0}}, \overline{x_{K}}\right\rangle$, $\bar{x} \in\left\langle\overline{x_{K}}, \overline{x_{K w}}\right\rangle$ and $\bar{x} \in\left\langle\overline{x_{K w}}, \overline{x_{M w}}\right\rangle$. In the interval $\bar{x} \in\left\langle 0, \overline{x_{O}}\right\rangle$ we use the coordinates of the transition curve $\overline{x_{2}}(l)$ and $\overline{y_{2}}(l)$ belonging to the interval and we determine the difference

$$
\Delta y^{(1)}=\overline{x_{2}}(l) \tan \frac{\alpha}{2}-\overline{y_{2}}(l)
$$


In the interval $\bar{x} \in\left\langle\overline{x_{0}}, \overline{x_{K}}\right\rangle$ by interpolation, we determine ordinates of the existing transition curve $\overline{y_{1}^{\text {lnt }}}$ for abscissa $\overline{x_{2}}(l)$ belonging to the interval. The difference or ordinates is

$$
\Delta y^{(2)}=\overline{y_{1}^{l n t}}-\overline{y_{2}}(l)
$$

In the interval $\bar{x} \in\left\langle\overline{x_{K}}, \overline{x_{K w}}\right\rangle$, we calculate the difference between the ordinates of the original circular arc designated for the abscises $\overline{x_{2}}(l)$ belonging to this interval and ordinates of the extended transition curve.

$$
\Delta y^{(3)}=\overline{y_{\mathrm{KK} 1}}\left[\overline{x_{2}}(l)\right]-\overline{y_{2}}(l)
$$

The equation of the original circular arc is as follows:

$$
\overline{y_{\mathrm{E} K 1}}(\bar{x})=\overline{y_{K}}+\left[R^{2}-\left(\overline{x_{M}}-\bar{x}\right)^{2}\right]^{\frac{1}{2}}-\left[R^{2}-\left(\overline{x_{M}}-\overline{x_{K}}\right)^{2}\right]^{\frac{1}{2}}
$$

In the interval $\bar{x} \in\left\langle\overline{x_{K w}}, \overline{x_{M w}}\right\rangle$ difference in ordinates concerns the original position of the arc and the arc shifted by the extension of the transition curves.

$$
\Delta y^{(4)}=\overline{y_{Ł K 1}}(\bar{x})-\overline{y_{Ł K 2}}(\bar{x})
$$

The equation of shifted circular arc is as follows:

$$
\overline{y_{Ł K 2}}(\bar{x})=\overline{y_{K w}}+\left[R^{2}-\left(\overline{x_{M w}}-\bar{x}\right)^{2}\right]^{\frac{1}{2}}-\left[R^{2}-\left(\overline{x_{M w}}-\overline{x_{K w}}\right)^{2}\right]^{\frac{1}{2}}
$$

\section{Change of the radius of the circular arc}

Theoretical relations given in sections 3.2 and 3.3 concerned the situation when during the extension of the transition curves is retained the value of the arc radius $R$. However, there is also a possibility of changing the radius of the circular arc.

The inclusion of the radius $R_{w}$ causes the changes of parametric equations $x_{w}(l)$ and $y_{w}(l)$ in the geometrical system with the elongated transition curve. As a result, the equations $\overline{x_{2}}(l)$ and $\overline{y_{2}}(l)$ as well as coordinates of points $K_{w}$ and $M_{w}$ are also subjected to a change. The slope of the tangent at the end of the elongated transition curve is

$$
\overline{S_{K w}}=\tan \left(-\frac{l_{w}}{2 R_{w}}+\frac{\alpha}{2}\right)
$$

Of course, changing the radius of the circular arc is also a need for a correction in the equation (22).

\section{Problem analysis for different radii of the circular arc}

Table 1 shows the analysed cases of geometric systems. It was assumed the raise of train speed to $20 \mathrm{~km} / \mathrm{h}$ on each of these systems, obtained by the extending the transitional curves. 
Table 1. Case studies of geometric systems

\begin{tabular}{|c|c|c|c|c|}
\hline $\begin{array}{c}\text { Radius of the } \\
\text { circular arc } R \\
\text { [m] }\end{array}$ & State & $\begin{array}{l}\text { Lean on the arc } h \\
{[\mathrm{~mm}]}\end{array}$ & $\begin{array}{c}\text { Length of the } \\
\text { transition curve } l \\
{[\mathrm{~m}]}\end{array}$ & $\begin{array}{c}\text { Speed trains } v \\
{[\mathrm{~km} / \mathrm{h}]}\end{array}$ \\
\hline 500 & $\begin{array}{l}\text { Existing } \\
\text { After } \\
\text { modernization }\end{array}$ & $\begin{array}{c}80 \\
120\end{array}$ & $\begin{array}{c}70 \\
120\end{array}$ & $\begin{array}{c}80 \\
100\end{array}$ \\
\hline 800 & $\begin{array}{l}\text { Existing } \\
\text { After } \\
\text { modernization }\end{array}$ & $\begin{array}{l}90 \\
90\end{array}$ & $\begin{array}{c}90 \\
110\end{array}$ & $\begin{array}{l}100 \\
120\end{array}$ \\
\hline 1500 & $\begin{array}{l}\text { Existing } \\
\text { After } \\
\text { modernization }\end{array}$ & $\begin{array}{l}50 \\
80\end{array}$ & $\begin{array}{c}70 \\
130\end{array}$ & $\begin{array}{l}140 \\
160\end{array}$ \\
\hline
\end{tabular}

Let us consider first the case $R=500 \mathrm{~m}$ at the angle of return route $\propto=45^{\circ}$. Table 2 shows the characteristic values for the geometrical system. It also contains the values obtained after reducing the radius of the circular arc to $R=489 \mathrm{~m}, 488 \mathrm{~m}$ and $486 \mathrm{~m}$.

Table 2. The characteristic values for the selected geometric systems at the angle $\propto=45^{\circ}$

\begin{tabular}{|c|c|c|c|c|c|c|c|c|c|}
\hline $\begin{array}{c}R \\
{[\mathrm{~m}]}\end{array}$ & $\begin{array}{c}\overline{x_{0}} \\
{[\mathrm{~m}]}\end{array}$ & $\begin{array}{c}\overline{y_{0}} \\
{[\mathrm{~m}]}\end{array}$ & $\begin{array}{c}\overline{x_{K}} \\
{[\mathrm{~m}]}\end{array}$ & $\begin{array}{c}\overline{y_{K}} \\
{[\mathrm{~m}]}\end{array}$ & $\begin{array}{c}\overline{x_{K w}} \\
{[\mathrm{~m}]}\end{array}$ & $\begin{array}{c}\overline{y_{K w}} \\
{[\mathrm{~m}]}\end{array}$ & $\begin{array}{c}\overline{x_{M w}} \\
{[\mathrm{~m}]}\end{array}$ & $\begin{array}{c}\overline{y_{M w}} \\
{[\mathrm{~m}]}\end{array}$ & $\begin{array}{c}\Delta y_{M} \\
{[\mathrm{~m}]}\end{array}$ \\
\hline 500 & 23.378 & 9.684 & 88.643 & 34.950 & 112.541 & 41.426 & 247.207 & 59.902 & 0.856 \\
\hline 489 & 19.178 & 7.944 & 84.443 & 33.210 & 112.575 & 41.323 & 243.006 & 59.039 & -0.021 \\
\hline 488 & 18.796 & 7.786 & 84.061 & 33.052 & 112.578 & 41.314 & 242.625 & 58.961 & -0.101 \\
\hline 486 & 18.033 & 7.469 & 83.297 & 32.736 & 112.584 & 41.295 & 241.861 & 58.804 & -0.260 \\
\hline
\end{tabular}

While maintaining the existing radius circular arc $R=500 \mathrm{~m}$ the difference between ordinates in the middle of the geometric system is $\Delta y_{M}=0.856 \mathrm{~m}$. However, the full understanding of the situation gives only determination of differences between ordinates of the existing geometric and modified systems along the entire length. For this purpose, we used formulas (17), (18), (19) and (21). The corresponding diagram is shown in Figure 2.

As you can see, the differences between ordinates grow smoothly in the interval $\bar{x} \in$ $\left\langle 0, \overline{x_{O}}\right\rangle$, and then in the range $\bar{x} \in\left\langle\overline{x_{0}}, \overline{x_{K}}\right\rangle$ they rapidly grow. In the next interval $\bar{x} \in$ $\left\langle\overline{x_{K}}, \overline{x_{K w}}\right\rangle$ there is a smooth transition to a constant difference characterizing the region circular arc displaced as a result of the extending the transitional curves. This difference is not only relatively high, but it occurs in a considerable length, clearly longer than the half the length of the entire geometric system.

On this basis, it can be concluded that the extension of the transitional curves while maintaining the existing circular arc radius is not the preferred solution and the radius should be reduced. The main issue is to determine the degree of this reduction. 


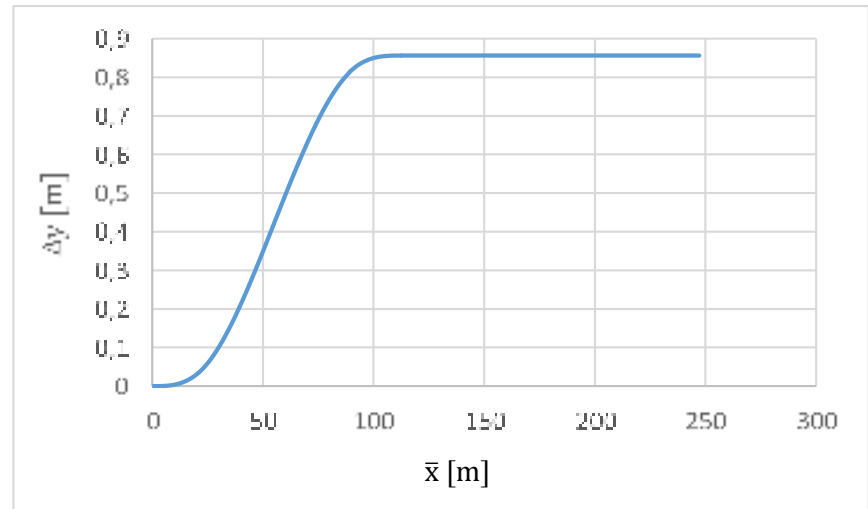

2. Chart of differences in ordinates along the length of the modified geometric system for $R=$ $500 \mathrm{~m}, l_{k}=70 \mathrm{~m}, l_{w}=120 \mathrm{~m}$ and $\propto=45^{\circ}$

Gradually reducing the existing radius of the circular $\operatorname{arc} R=500 \mathrm{~m}$ we obtained smaller and smaller values of the index $\Delta y_{M}$. The lowest values were characterized by the radii of horizontal arches listed in Table 2. The full picture of the situation is presented by charts of differences in ordinates, shown in Figure 3.

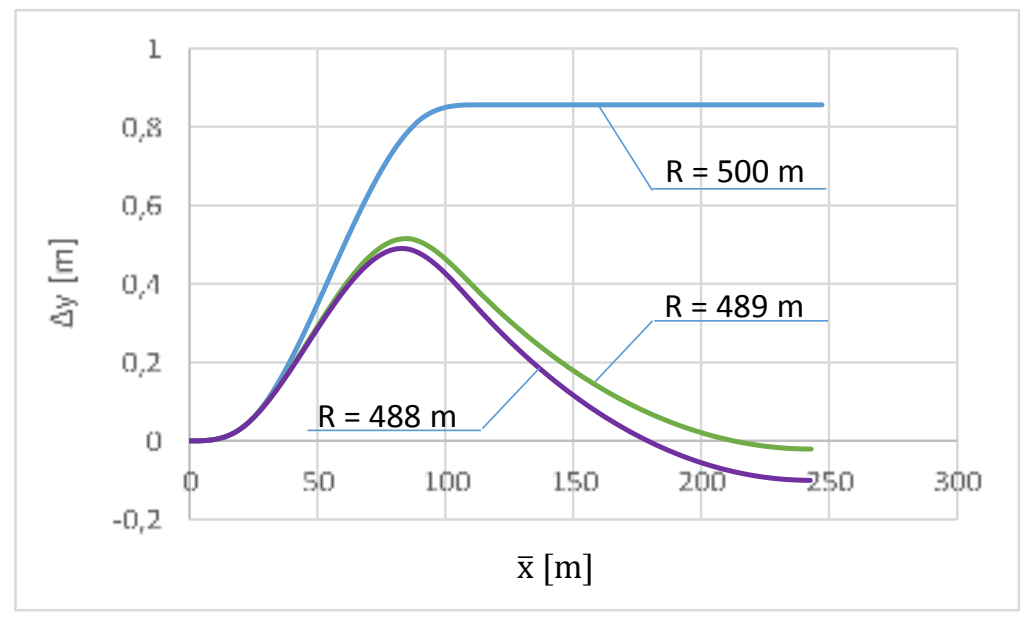

3. Chart of differences in ordinates along the length of the modified geometric system for $R=$ $500 \mathrm{~m}, 489 \mathrm{~m}$ and $488 \mathrm{~m}, l_{k}=70 \mathrm{~m}, l_{w}=120 \mathrm{~m}\left(\propto=45^{\circ}\right)$

Figure 3 clearly shows that the reduction of the radius of the circular arc will not only significantly reduce the maximum value of the necessary crosswise shift occurring locally in the region of the end of the existing transition curve, but above all it dramatically reduces the shift of the circular arc. As the most beneficial option should be considered the variant using the radius $R=489 \mathrm{~m}$, requiring somewhat larger shifts in the region of the end of the existing transition curve than is the case for $R=488 \mathrm{~m}$, characterizing, however, by smaller shift along the length of the circular arc.

In the same way, other cases of geometric system in Table 1 were considered for the return angle $\propto=45^{\circ}$. Figures 4 and 5 show the results of the analysis. 


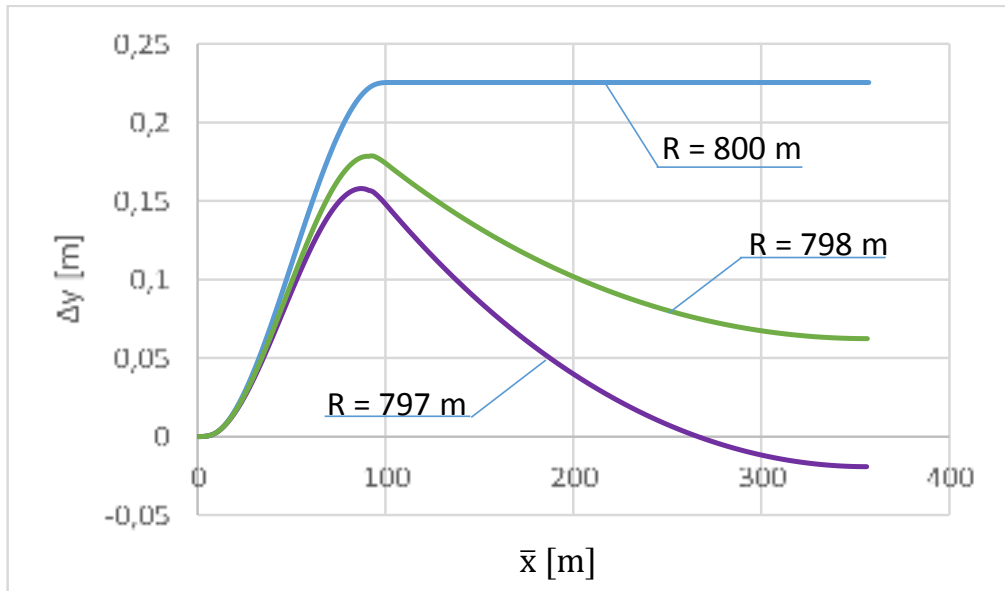

4. Chart of differences in ordinates along the length of the modified geometric system for $R=$ $800 \mathrm{~m}, 798 \mathrm{~m}$ and $797 \mathrm{~m}, l_{k}=90 \mathrm{~m}, l_{w}=110 \mathrm{~m}\left(\propto=45^{0}\right)$

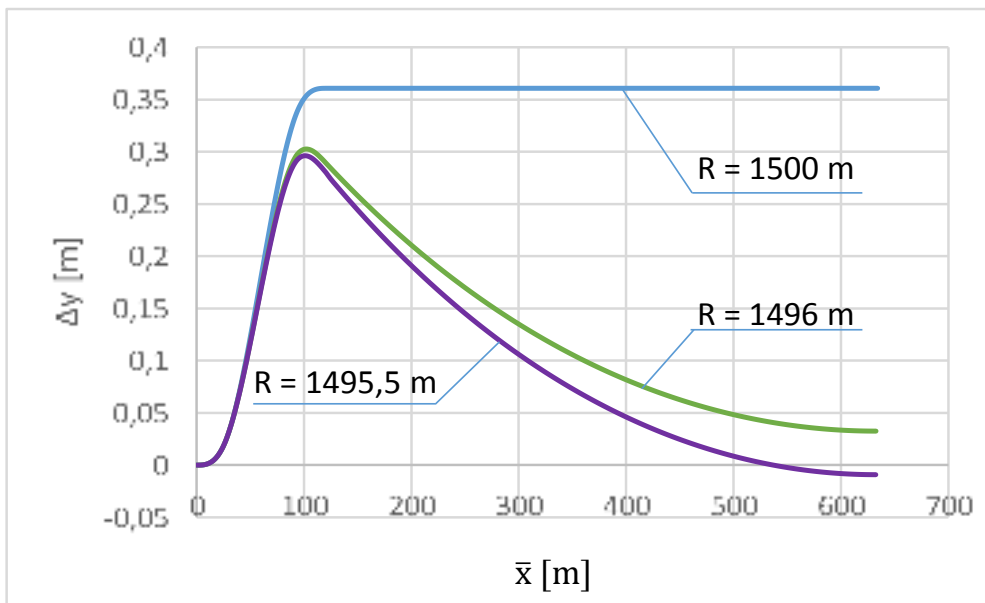

5. Chart of differences in ordinates along the length of the modified geometric system for $R=$ $1500 \mathrm{~m}, 1496 \mathrm{~m}$ and $1495.5 \mathrm{~m}, l_{k}=70 \mathrm{~m}, l_{w}=130 \mathrm{~m}\left(\propto=45^{0}\right)$

In Figures 4 and 5 results that for the larger radii of circular arcs, the value of necessary vertical shift may be less than it is in Figure 2 with maintaining the existing radius. The reducing the radius of the arc improves radically the situation. It should be noted that with the increasing the radius the magnitude of this decrease becomes smaller and smaller in percentage terms. In the considered examples, it amounts to $2.2 \%$ for $R=500 \mathrm{~m}, 0.375 \%$ for $R=800 \mathrm{~m}$ and $0,267 \%$ for $R=1500 \mathrm{~m}$. As can be seen, these values are very small.

\section{Analysis of the angle impact of the return route}

The analysis carried out in the section 4 dealt with the case of a relatively small angle of return route $\propto=45^{\circ}$. At the current stage, we consider the impact of the angle of the return route on obtained geometric solutions. Figures 6 to 11 show, as before, plots of differences in ordinates for $\propto=90^{\circ}$ and $\propto=135^{\circ}$. 


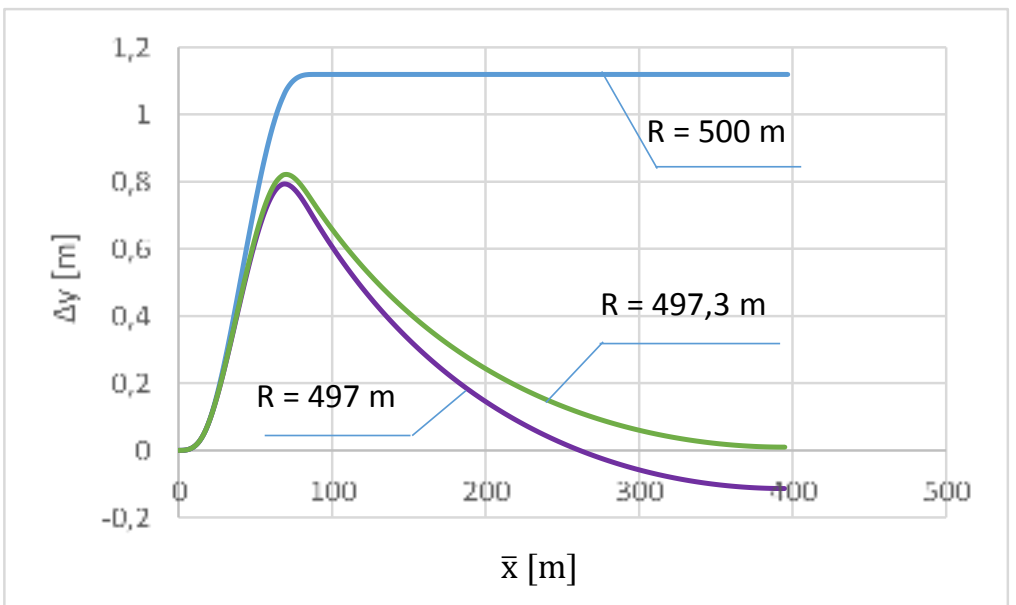

6. Chart of differences in ordinates along the length of the modified geometric system for $R=$ $500 \mathrm{~m}, 497 \mathrm{~m}$ and $497.3 \mathrm{~m}, l_{k}=70 \mathrm{~m}, l_{w}=120 \mathrm{~m}\left(\propto=90^{\circ}\right)$

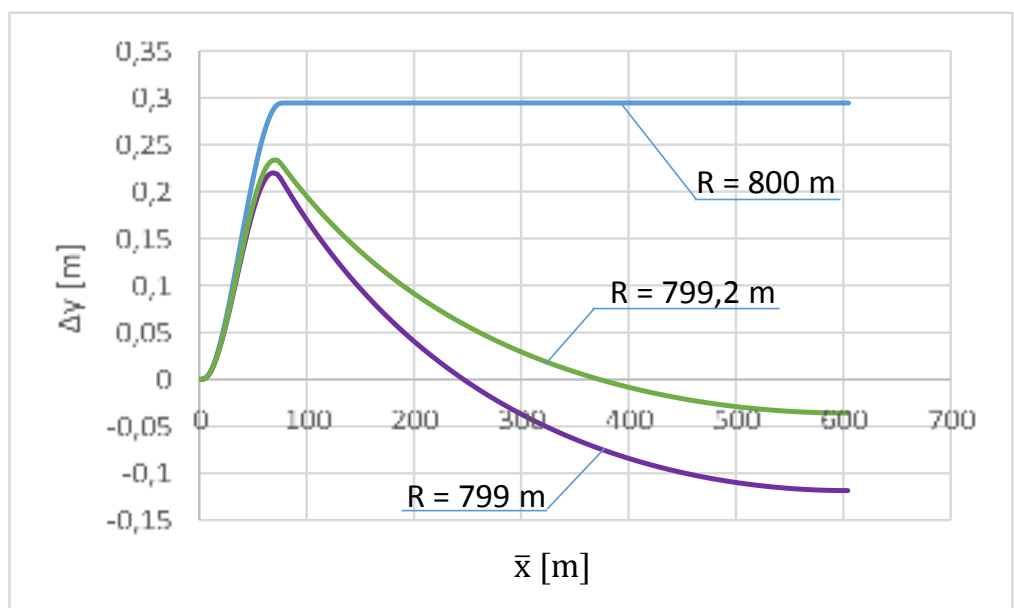

7. Chart of differences in ordinates along the length of the modified geometric system for $R=$ $800 \mathrm{~m}, 799 \mathrm{~m}$ and $799.2 \mathrm{~m}, l_{k}=90 \mathrm{~m}, l_{w}=110 \mathrm{~m}\left(\propto=90^{\circ}\right)$

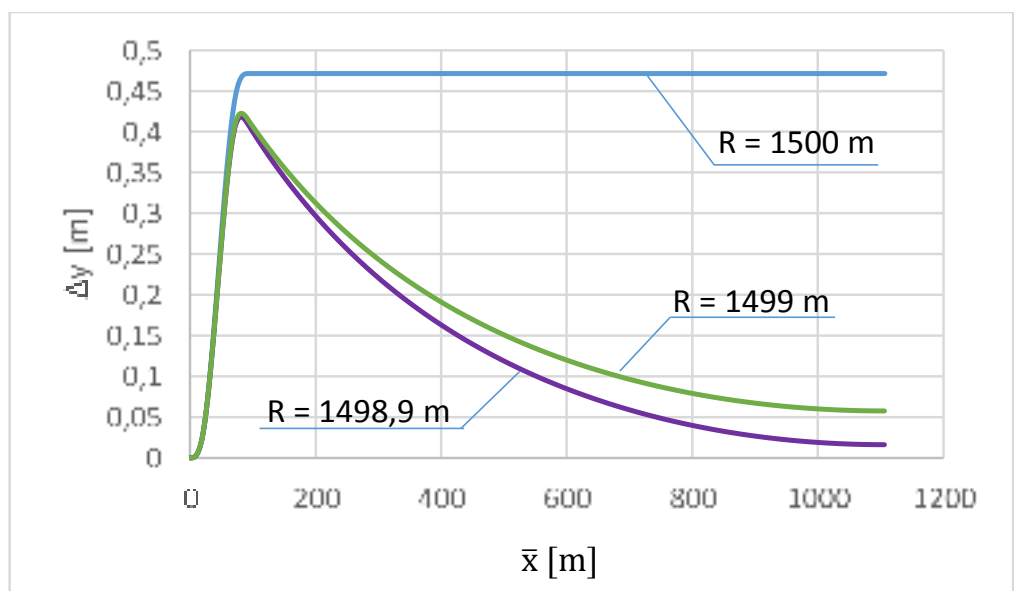

8. Chart of differences in ordinates along the length of the modified geometric system for $R=$ $1500 \mathrm{~m}, 1499 \mathrm{~m}$ and $1498.9 \mathrm{~m}, l_{k}=70 \mathrm{~m}, l_{w}=130 \mathrm{~m}\left(\alpha=90^{\circ}\right)$ 


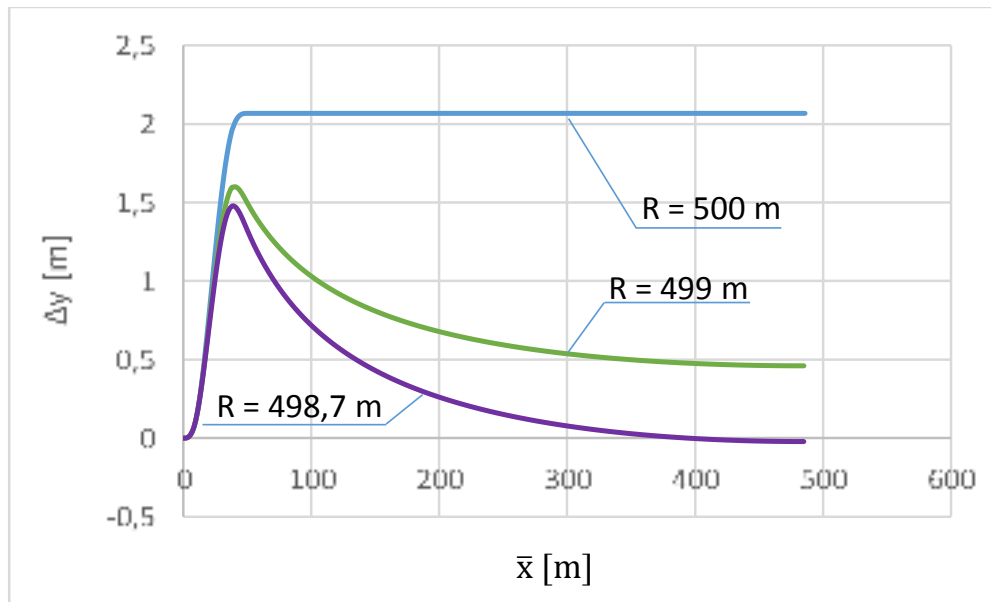

9. Chart of differences in ordinates along the length of the modified geometric system for $R=$ $500 \mathrm{~m}, 499 \mathrm{~m}$ and $498.7 \mathrm{~m}, l_{k}=70 \mathrm{~m}, l_{w}=120 \mathrm{~m}\left(\propto=135^{\circ}\right)$

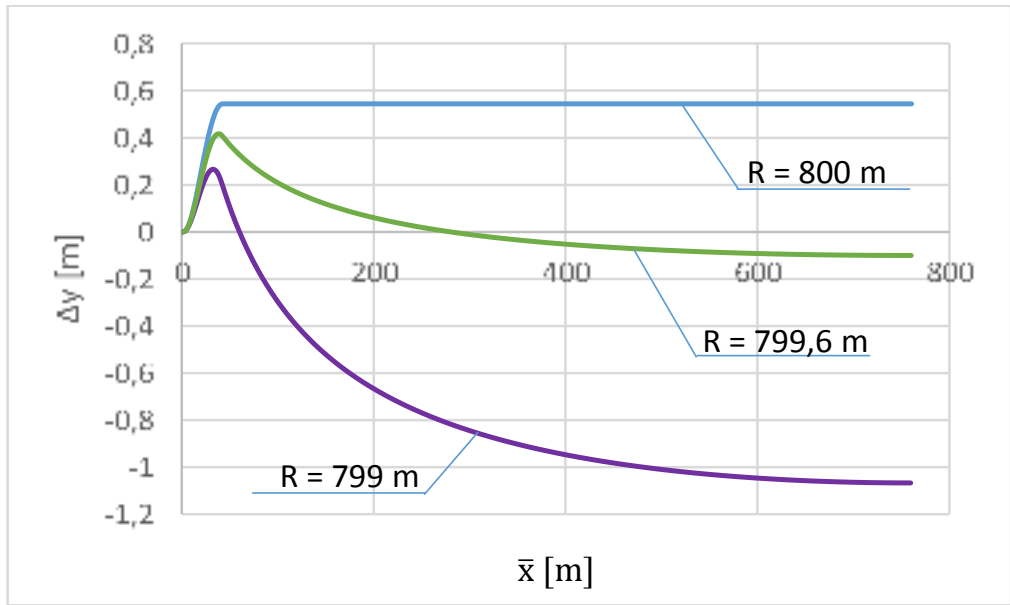

10. Chart of differences in ordinates along the length of the modified geometric system for $R$ $=800 \mathrm{~m}, 799 \mathrm{~m}$ and $799.6 \mathrm{~m}, l_{k}=90 \mathrm{~m}, l_{w}=110 \mathrm{~m}\left(\propto=135^{0}\right)$ 


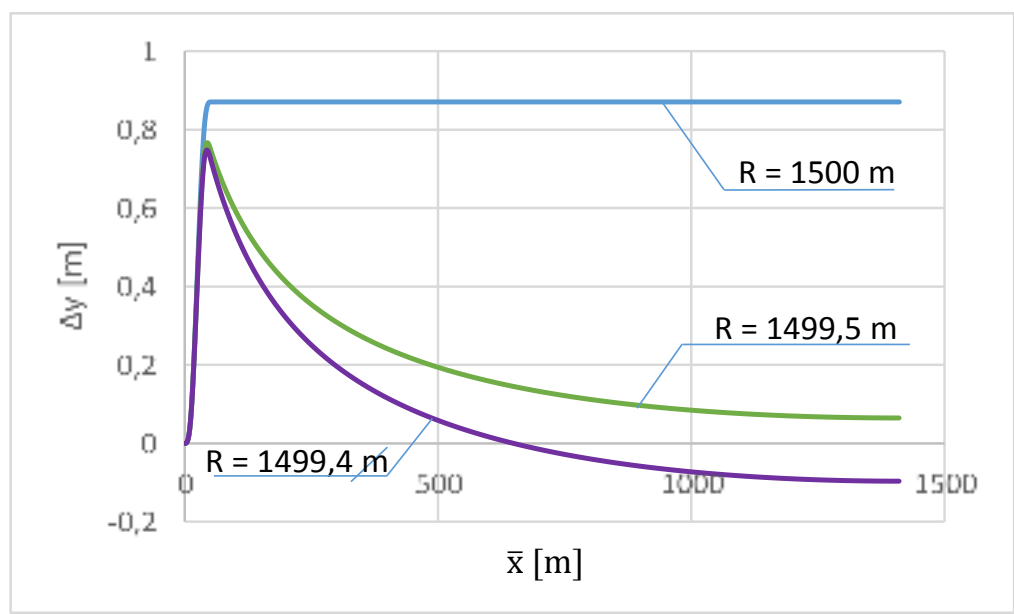

11. Chart of differences in ordinates along the length of the modified geometric system for $R$ $=1500 \mathrm{~m}, 1499.5 \mathrm{~m}$ and $1499,4 \mathrm{~m}, l_{k}=70 \mathrm{~m}, l_{w}=130 \mathrm{~m}\left(\propto=135^{0}\right)$

Table 3 shows characteristic values of considered geometrical systems for different angles of return route $\propto$.

Table 3. Characteristic values for the different angles of the return route $\propto$

\begin{tabular}{|c|c|c|c|c|c|c|c|c|c|}
\hline $\begin{array}{c}\propto \\
{[\text { stop] }}\end{array}$ & $\begin{array}{c}R \\
{[\mathrm{~m}]}\end{array}$ & $\begin{array}{c}\Delta y_{\max } \\
{[\mathrm{m}]}\end{array}$ & $\begin{array}{c}\Delta y_{M} \\
{[\mathrm{~m}]}\end{array}$ & $\begin{array}{c}R \\
{[\mathrm{~m}]}\end{array}$ & $\begin{array}{c}\Delta y_{\max } \\
{[\mathrm{m}]}\end{array}$ & $\begin{array}{c}\Delta y_{M} \\
{[\mathrm{~m}]}\end{array}$ & $\begin{array}{c}R \\
{[\mathrm{~m}]}\end{array}$ & $\begin{array}{c}\Delta y_{\max } \\
{[\mathrm{m}]}\end{array}$ & $\begin{array}{c}\Delta y_{M} \\
{[\mathrm{~m}]}\end{array}$ \\
\hline \multirow{3}{*}{45} & 500 & 0.856 & 0.856 & 800 & 0.225 & 0.225 & 1500 & 0.361 & 0.361 \\
\hline & 489 & 0.515 & -0.021 & 798 & 0.179 & 0.062 & 1496 & 0.302 & 0.033 \\
\hline & 488 & 0.488 & -0.101 & 797 & 0.158 & -0.019 & 1495.5 & 0.300 & -0.009 \\
\hline \multirow{3}{*}{90} & 500 & 1.119 & 1.119 & 800 & 0.295 & 0.295 & 1500 & 0.471 & 0.471 \\
\hline & 497 & 0.793 & -0.114 & 799 & 0.220 & -0.119 & 1499 & 0.423 & 0.058 \\
\hline & 497.3 & 0.821 & 0.010 & 799.2 & 0.234 & -0.034 & 1498.9 & 0.418 & 0.016 \\
\hline \multirow{3}{*}{135} & 500 & 2.067 & 2.067 & 800 & 0.544 & 0.544 & 1500 & 0.871 & 0.871 \\
\hline & 499 & 1.600 & 0.460 & 799 & 0.266 & -1.067 & 1499.5 & 0.767 & 0.065 \\
\hline & 498.7 & 1.478 & -0.022 & 799.6 & 0.417 & -0.100 & 1499.4 & 0.748 & -0.096 \\
\hline
\end{tabular}

The presented graphs and numerical data in Table 3 show that even the substantial prolongation of the transition curves, e.g. from $70 \mathrm{~m}$ to $120 \mathrm{~m}$, does not necessarily require so large crosswise movements around the geometric system, as it is commonly believed (in most of the examples $\Delta y<1 \mathrm{~m}$ ). For a given angle of return route $\propto$ values $\Delta y$ decrease with the increasing the radius of the circular arc $R$, and the increase in $\propto$ causes the growth of $\Delta y$.

The behaviour of the existing radius $R$ in the elongation of the transition curve it is not a preferred solution as the value of $\Delta y$ grows rapidly over the length of transition curve to obtain a constant value on the circular arc.

The reducing the existing radius $R$ radically decreases the value $\Delta y$ on the circular arc. In the middle area it is possible even to avoid the need of track displacement. Maximum values $\Delta y$ occur locally in the region of the end of the existing transition curve and the adjacent section of the elongated transition curve. They are in any case less than the fixed $\Delta y$ on the circular arc in the case of maintaining its radius. 
The required reduction of the radius of the circular arc turns out to be surprisingly small and becoming smaller with increasing $R$ in percentages terms. For small angles $\propto$ there are single meters, whereas for the large $\propto$ the decreasing $R$ may be only a few dozen centimetres.

\section{Conclusions}

The analytical design method allowed looking at the problem of extending the transition curves with a slightly different perspective. Some observations can seem quite surprising and standing out from the existing common opinion. As it turns out, the extension of the transition curve does not have to cause large crosswise displacement of the existing track at a considerable length. It is only necessary to reduce in a suitable way the radius of the circular arc.

The reducing the radius of the circular arc causes the dramatic reduction of the necessary crosswise displacements of the track, and in the centre area of the arc it becomes possible to completely eliminate them. It should be noted that the required reduction in the arc radius is limited to a small range. They are individual meters or just tens of centimetres. The shift values decrease with the increasing the radius of the circular arc, and grow with the increasing the angle of the return route.

The presented in the paper theoretical relationships allow analysing the symmetrical geometric system. In the presence of varying length of the transition curve, the action should be slightly modified, but the basic conclusions of this work and will be retained.

\section{Source materials}

[1] Bałuch H.: Optymalizacja układów geometrycznych toru. WKŁ, Warszawa 1983.

[2] Bałuch H., Bałuch M.: Determinanty prędkości pociągów - układ geometryczny i wady toru. Instytut Kolejnictwa, Warszawa 2010.

[3] Bałuch H., Bałuch M.: Układy geometryczne toru i ich deformacje. PKP Polskie Linie Kolejowe S.A., Warszawa 2010.

[4] Koc W.: Analiza dynamiczna wydłużania krzywych przejściowych przy odchyleniu stycznej do łuku. Zesz. Nauk. Pol. Gdańskiej 1991, nr 459, seria Budownictwo Lądowe XLVI.

[5] Koc W.: Metoda projektowania rejonu zmiany kierunku trasy kolejowej. Problemy Kolejnictwa 2011, zeszyt 152.

[6] Koc W.: Projektowanie łuków koszowych dostosowane do pomiarów satelitarnych. Prace Naukowe Politechniki Warszawskiej, seria Transport, z. 98, 2013.

[7] Koc W.: Projektowanie rejonu zmiany kierunku trasy kolejowej w zapisie matematycznym. Przegląd Komunikacyjny 2012, nr 7-8.

[8] Koc W.: Zasadność utrzymywania założeń upraszczających w projektowaniu układów geometrycznych toru. Infrastruktura Transportu 2014, nr 3. 